\title{
The Determinants to Promote College Students' Use of Car-Sharing: An Empirical Study at Dalian Maritime University, China
}

\author{
Shichao Sun ${ }^{1}$, Yuanqian Liu ${ }^{2}$, Yukun Yao ${ }^{1}$, Zhengyu Duan ${ }^{3}$ and Xiaokun Wang ${ }^{4,5, *}$ \\ 1 College of Transportation Engineering, Dalian Maritime University, Dalian 116026, China; \\ sunshichao@dlmu.edu.cn (S.S.); 15904260198@163.com (Y.Y.) \\ 2 School of Mechanical and Electrical Engineering, Guangzhou University, Guangzhou 510006, China; \\ liuyuanqian97@outlook.com \\ 3 Key Laboratory of Road and Traffic Engineering of the Ministry of Education, Tongji University, \\ Shanghai 201804, China; d_zy@163.com \\ 4 School of Economics and Management, Dalian Jiaotong University, Dalian 116028, China \\ 5 Research Institute of the Belt and Road, Dalian Jiaotong University, Dalian 116028, China \\ * Correspondence: wxk@djtu.edu.cn
}

check for updates

Citation: Sun, S.; Liu, Y.; Yao, Y.;

Duan, Z.; Wang, X. The Determinants to Promote College Students' Use of Car-Sharing: An Empirical Study at Dalian Maritime University, China. Sustainability 2021, 13, 6627.

https://doi.org/10.3390/su13126627

Academic Editor: Marilisa Botte

Received: 3 May 2021

Accepted: 7 June 2021

Published: 10 June 2021

Publisher's Note: MDPI stays neutral with regard to jurisdictional claims in published maps and institutional affiliations.

Copyright: (c) 2021 by the authors. Licensee MDPI, Basel, Switzerland. This article is an open access article distributed under the terms and conditions of the Creative Commons Attribution (CC BY) license (https:// creativecommons.org/licenses/by/ $4.0 /)$.

\begin{abstract}
Sustaining the development of car-sharing is considered an efficient way to counter environmental issues worldwide. Against this background, college students are recognized as a promising customer group of car-sharing service providers in China. However, the determinants that promote students' willingness to use car-sharing services are rarely studied, and the uniqueness of college students in China in the context of car-sharing is justified. Therefore, this paper examines the key factors that affect Chinese college students' adoption of car-sharing. An empirical study using samples from Dalian Maritime University was conducted, and survey data were collected via the Internet. Specifically, respondents' socio-demographics were obtained, and their latent attitudes on car-sharing services were measured in terms of willingness to use car-sharing services, perceived usefulness, perceived ease of use and safety concerns. In addition, nine hypothetical travel scenarios were defined, and regarding each travel scenario, the respondents were asked to state whether they were willing or not to use car-sharing services. On this basis, a hybrid logit model was established to investigate the key factors that influenced the willingness to use car-sharing services. Aside from the common findings in line with previous studies, the results indicate that with the increase in the number of travel fellows, willingness to use car-sharing services went up. Furthermore, college students' willingness to use car-sharing services was significantly affected by money costs rather than time costs. Additionally, college students in China are more likely to use car-sharing services during workday off-peak hours and weekends. Separately, among the respondents' latent attitudes, only the perceived usefulness of car-sharing services was found to have a significant and positive impact on students' willingness to use them. Relevant policy implications with regards to theoretical findings are also offered in this paper to car-sharing service providers in China.
\end{abstract}

Keywords: car-sharing; influence factors; college students; hybrid choice model; policy implications

\section{Introduction}

Ever since the Mobike and Ofo projects (stationless bike-sharing services) were launched in 2016, the sharing economy has gained popularity in China in recent years [1]. Combined with the wide application of information and communication technologies, the impacts of the sharing economy are much more significant on maximizing resources use, minimizing land use and sustaining the environment [2]. As an important component of the sharing economy, car-sharing has been long considered as a novel alternative to private car ownership worldwide [3]. Especially in European cities, car-sharing has been 
adopted as a smart solution to foster more sustainable mobility for decades [4]. For instance, 1.3 million new car-sharing users in Italy were registered on operators' platforms in 2017, increasing by $21 \%$ versus 2016 [5]. In contrast, car-sharing services started later in China, but developed much more rapidly. The first industrial car-sharing company (EVnet) in China was established in 2010, and nowadays it has more than 10 million registered members around the country [6]. Regardless of the practices in Europe and China, it indicated that the service form of car-sharing indeed has the potential to alleviate air pollution, reduce the use of private cars and thus contribute to a sustainable transportation system [7-9]. Therefore, in the context of car-sharing, lifting its market share to expand the influence in dense urban areas seems to be an effective way to counter environmental and societal issues [7,10-12]. Thus, understanding key factors that drive consumers to adopt car-sharing is important to result in providing targeted demand-oriented services [13,14].

However, attitudes on service quality and service satisfaction of car-sharing differ between heterogeneous customers. In this context, this implies that high-quality services must be tailored for different customer groups [11,15]. Among customer groups of carsharing operators, college students can be recognized as a large promising group. The reasons are twofold. First, college students aged from 18 to 28 years old are generally receptive to the concept of the sharing economy [16]. Thus, the service form of car-sharing is more acceptable to college students. Second, college students are usually characterized as holding limited disposable income and having low car ownership $[1,17,18]$. A recent report showed that $90 \%$ of college students in Rome, Italy, held driver's licenses, but only 35\% of them owned private cars [17]. Given this, car-sharing can provide favorable conditions for college students to realize private motorization without owning a car. Although public transport has much lower fares, travel-by-car seems to have a very special symbolic meaning. Especially in China, private motorization has been regarded as a symbol of success for decades [18]. Meanwhile, car-sharing also offers a more flexible and comfortable travel experience, compared with conventional public transport. Thus, it is reasonable to regard car-sharing as a competitive alternative to both public transport and private cars for college students. As a consequence, a separate and segment-specific study should be conducted to offer insights on key factors that influence college students' adoptions of car-sharing $[17,19]$.

However, very few studies have ever pursued separate investigations on examining the factors that have significant effects on college students' adoption of car-sharing. To the best of our knowledge, the only targeted studies were concentrated at universities of Western countries, namely the University of Wisconsin, Madison, the University of California, Los Angeles, and the University of Trieste, Italy [20-23]. Thus, the findings provided by these relevant studies could not be generalizable for applying to Chinese college students because there is a significant difference between college students in China and their counterparts in Western countries. The uniqueness of researching Chinese college students in the context of car-sharing can be summarized as follows.

(1) The lifestyle of college students in China is quite different from the general samples involved in previous studies. Specifically, the vast majority of college students in China, including undergraduates and postgraduates, live in the dormitories provided by universities. The dormitories are generally located on campus. Thus, from the perspective of trip purposes, college students in China rarely commute, which is different from the situations in Western countries. However, trip purpose is widely recognized as the key factor that influences the transport mode choice. Thus, because of the inconsistency of travel scenarios between college students in China and in Western countries, a segment-specific and separate investigation should be conducted on Chinese college students to distinguish the differences.

(2) As mentioned above, in China, travel-by-car is regarded as a symbol of success to some extent. In this context, car-sharing offers a good opportunity for college students in China to realize private motorization without owning a car. Thus, the service form of car-sharing may be more attractive to the college students in China. Beyond the common 
reasons that college students have low car ownership but are willing to use cars, the symbolic meaning of travel-by-car can be seen as another strong motivation for college students in China to adopt the sharing service. Thus, the research on Chinese college students is unique in the context of car-sharing with regard to this point.

(3) The development of car-sharing in China is still in early stages, thus leaving much room for improvement in terms of service quality, diversity of service content, related laws and regulations and safety guarantee. Nevertheless, associated with the intervention of Internet capital, the process is pushed forward rapidly and dynamically, and many competitors want to seize for the market share of car-sharing. Thus, under the current circumstance, the key factors that influence college students in China to use car-sharing services may be different from other countries.

In short, this tailored research distinguishes itself by uncovering key driving factors of college students in China to use car-sharing services. In addition, this paper is also motivated to shed light on targeted strategies that would promote the growth of car-sharing markets. The remainder of this paper is organized as follows. Section 2 gives a literature review related to car-sharing use. Section 3 states the details of survey data collection and processing. Section 4 presents relevant methods, including factor analysis, path analysis and hybrid logit regression with latent variables. Section 5 discusses the results, and then proposes targeted promotion policies and strategies for the increase in market share. Section 6 summarizes the conclusion and study limitations.

\section{Literature Review}

A large number of studies have investigated the key factors that determine the willingness to use car-sharing services. Specifically, causal models, such as logit or probit models [13,23-27] and structural equation models [2,28-30], are commonly used to examine the relationships between potential influencing variables and respondents' car-sharing willingness-of-use. Regardless of the type of models established in the previous studies, the relevant findings showed that the common key factors can be summarized as follows.

First, numerous studies have reported that the willingness to use car-sharing services was greatly impacted by individual differences, such as age [31-34], household income [35,36], household size [37,38], education [39-41] and occupation [20,33]. Efthymiou, Antoniou and Waddell [24] indicated that younger people with a higher education level were more likely to use car-sharing services. In addition, it is generally found that high income, living in urban centers or high-density areas and small house size increased the possibility of using car-sharing services [3,17,25,28].

Second, the service quality of car-sharing was demonstrated to exert an important influence on the adoption of car-sharing. Kim, Rasouli and Timmermans [34] found that the potential users' overall satisfaction towards the travel attributes of car-sharing would seriously affect their use intention. Specifically, the size of the car fleet [34], ease of use (complexity of reservation process, etc.) [42], travel cost (time cost and rental cost) [43], usefulness of service (reliability, efficiency and security) [1] and registration fee [3] were found to be the significant predictors of willingness to use car-sharing services.

Additionally, the residents' latent attitudes on car-sharing services were also of great importance to affect the adoption intention of car-sharing. Jin, Yao and An [8] investigated the key factors that influenced the adoption of car-sharing services in Beijing, China, in terms of respondents' latent attitudes, level of service and local vehicle restriction policies. By using samples collected in Netherlands, Kim, Rasouli and Timmermans [42] similarly examined the relationship between users' latent attitudes towards car-sharing services and their intention to adopt it. Basically, the results of the above studies both indicated that users' attitudes related to social benefit, usefulness of car-sharing, ease of use and privacy security turn out to be significant influencing factors.

Nevertheless, most of the above studies did not conduct a segment-specific and separate investigation on the intention of car-sharing adoption of college students. In fact, relevant discussions specifically of college students were not rich in the literature. Only few 
studies explored college students' willingness to use car-sharing services at the University of Wisconsin, Madison, the University of California, Los Angeles and the University of Trieste, Italy [20-23]. The results indicated that college students as a segmented customer group were more likely to adopt car-sharing services than others. Gender, age, income level and car ownership were demonstrated as important influencing factors. However, as we discussed, these findings were not generalizable for Chinese college students, and empirical studies for college students in China were rare. Therefore, this paper tried to bridge the gap, and incorporated the above relevant findings as candidate variables into a causal model to explore the key influencing factors with regard to college students in China.

\section{Survey Data}

Car-sharing services have different forms, but one-way services with fixed stations are mainstream in China $[8,44,45]$ because electric vehicles account for a very large proportion of the car fleets that serve the market $[8,46,47]$. Thus, service providers must guarantee that these electric vehicles are being charged at designated stations. Moreover, this service form is also known as station-based car-sharing, which implies that users can pick up and return vehicles at different designated stations [45]. Therefore, by default, we mainly collected respondents' attitudes and willingness-of-use on the station-based one-way car-sharing services in the survey. Due to the impact of COVID-19, the survey had to be conducted online and was issued to the students of Dalian Maritime University in March 2020. The university is located in the urban area of Dalian, nearly $8 \mathrm{~km}$ away from the city center (People's Square). In addition, the campus is served by one metro line and one bus route, and car-sharing services are also accessible. Respondents were randomly sampled from the university, and a total of 345 valid samples were collected (over $1 \%$ of the whole).

\subsection{Socio-Economic Variables}

The questionnaire involved in the survey consisted of three parts. The first part was designed to obtain socio-economic characteristics of the respondents, such as gender, grade, disposable income, disciplines and other driving experience context. According to the statistics shown in Table $1,46.96 \%$ of the respondents were male and $53.04 \%$ were female. The majority of the samples were in the senior grade $(26.67 \%)$. Nevertheless, the grade distribution was relatively uniform. As for monthly disposable income, the respondents who declared over CNY 1500 (equivalent to about USD 210) only accounted for $24.06 \%$ of the total. This is in line with the general characteristics of college students in China, and also can be seen as the reason why they would like to use car-sharing services (relatively lower cost) rather than owning a private car. In addition, most of the respondents studied the disciplines of natural sciences $(50.72 \%)$ and social sciences $(45.51 \%)$. The result was consistent with the discipline settings of the university. Furthermore, $87.25 \%$ of the respondents had less than one year of actual driving experience, while over $90 \%$ had ever used car-sharing services (as a driver or a passenger).

Table 1. Descriptive statistics of socio-economic characteristics of respondents.

\begin{tabular}{cc}
\hline Characteristics & Statistic Description \\
\hline Gender & Male $(46.96 \%) ;$ Female $(53.04 \%)$ \\
Grade & Freshman $(18.26 \%) ;$ Sophomore $(20.29 \%) ;$ Junior $(15.36 \%) ;$ \\
Senior $(26.67 \%) ;$ Postgraduate $(19.42 \%)$
\end{tabular}




\subsection{Respondents' Attitudes towards Car-Sharing Service}

In the second part of the questionnaire, respondents' attitudes towards car-sharing services in terms of willingness to use them, perceived usefulness, perceived ease of use and safety concerns were investigated through a set of observed indicators (as shown in Table 2). The indicators were measured by using a five-point Likert scale. Scores of 1 to 5 represented "strongly disagree", "disagree", "neutral", "agree" and "strongly agree", respectively.

Table 2. Descriptions of observed variables in the questionnaire.

\begin{tabular}{cc}
\hline Indicator & Descriptions \\
$\mathrm{Y}_{1}$ & I am willing to use car-sharing services on my trips. \\
$\mathrm{Y}_{2}$ & I think my frequency of using car-sharing services will continue to increase in the future. \\
$\mathrm{Y}_{3}$ & I may choose car-sharing when travelling with friends and classmates. \\
$\mathrm{Y}_{4}$ & It seems easy to use car-sharing services proficiently. \\
$\mathrm{Y}_{5}$ & It seems easy to access car-sharing services. \\
$\mathrm{Y}_{6}$ & Car-sharing services may be very useful for my trips. \\
$\mathrm{Y}_{7}$ & Car-sharing services may improve travelling efficiency. \\
$\mathrm{Y}_{8}$ & Car-sharing services may allow travel planning to be more flexible. \\
$\mathrm{Y}_{9}$ & There seems to be no need to worry about personal information security when car-sharing. \\
$Y_{10}$ & There seems to be no need to worry about personal safety when car-sharing.
\end{tabular}

\subsection{Hypothetical Travel Scenarios}

As for the last part of the questionnaire, a stated-preference survey was conducted. Specifically, nine hypothetical travel scenarios were designed and issued to the respondents, and they were asked to state their willingness to use car-sharing services or not under each scenario. The travel scenarios were orthogonally defined in terms of trip distance, time to depart and the number of travel fellows (Table 3). Specifically, the university is located about $8 \mathrm{~km}$ away from the city center, and the longest diagonal distance of the urban area of Dalian is about $25 \mathrm{~km}$. Thus, trip distance hypothesized in the travel scenarios was set in three grades, namely short distance trip $(\leq 5 \mathrm{~km})$, medium distance trip $(6-15 \mathrm{~km})$ and long distance trip (16-25 km). In addition, workday peak hours, workday off-peak hours and the weekend were set as the typical depart times in the scenarios. The number of travel fellows was also considered as an important factor that influenced transport mode choice. We defined the attribute of the number of travel fellows as travel alone, travel with 1-2 persons and travel with a group of people ( $\geq 3$ persons). The actual average money costs and time costs of different scenarios with different transport mode choices are given in Table 4. In this regard, the average money cost and time cost were derived from car-sharing platforms and the navigation system provided by Baidu map. With regard to each travel scenario, respondents were asked to state whether they will use car-sharing services or not (denoted as a binary dependent variable).

Table 3. Descriptions of hypothetical travel scenarios.

\begin{tabular}{cccc}
\hline Scenario & Time to Depart & Trip Type & No. of Travel Fellows \\
\hline 1 & Workday peak time & Long $(16-25 \mathrm{~km})$ & $1-2$ persons \\
2 & Workday off-peak time & Medium $(6-15 \mathrm{~km})$ & 0 person \\
3 & Weekend & Medium $(6-15 \mathrm{~km})$ & $1-2$ persons \\
4 & Workday peak time & Short $(\leq 5 \mathrm{~km})$ & 0 person \\
5 & Workday off-peak time & Short $(\leq 5 \mathrm{~km})$ & $1-2$ persons \\
6 & Workday off-peak time & Long $(16-25 \mathrm{~km})$ & $\geq 3$ persons \\
7 & Weekend & Long $(16-25 \mathrm{~km})$ & 0 person \\
8 & Workday peak time & Medium $(6-15 \mathrm{~km})$ & $\geq 3$ persons \\
9 & Weekend & Short $(\leq 5 \mathrm{~km})$ & $\geq 3$ persons \\
\hline
\end{tabular}


Table 4. Travel cost for each hypothetical travel scenario.

\begin{tabular}{|c|c|c|c|c|c|}
\hline \multirow{2}{*}{\multicolumn{2}{|c|}{ Trip Distance Time to Use }} & \multicolumn{4}{|c|}{ Money Cost (CNY)/Time Cost (Minutes) } \\
\hline & & \multirow{2}{*}{$\begin{array}{c}\text { Car-Sharing } \\
10 / 18\end{array}$} & \multirow{2}{*}{$\begin{array}{c}\text { Bus } \\
1 / 27\end{array}$} & \multirow{2}{*}{$\begin{array}{c}\text { Metro } \\
2 / 10\end{array}$} & \multirow{2}{*}{$\begin{array}{c}\text { Taxi } \\
23 / 18\end{array}$} \\
\hline & Workday peak time & & & & \\
\hline $5 \mathrm{~km}$ & Workday off-peak time & $8 / 10$ & $1 / 15$ & $2 / 10$ & $14 / 10$ \\
\hline & Weekend & $9 / 14$ & $1 / 21$ & $2 / 10$ & $14 / 14$ \\
\hline \multirow{3}{*}{$\begin{array}{c}15 \mathrm{~km} \\
\text { Medium trip }\end{array}$} & Workday peak time & $28 / 45$ & $2 / 106$ & $4 / 37$ & $55 / 43$ \\
\hline & Workday off-peak time & $23 / 25$ & $2 / 59$ & $4 / 37$ & $34 / 24$ \\
\hline & Weekend & $25 / 35$ & $2 / 82$ & $4 / 37$ & $34 / 33$ \\
\hline \multirow{3}{*}{$\begin{array}{l}20 \mathrm{~km} \\
\text { Long trip }\end{array}$} & Workday peak time & $44 / 66$ & $3 / 125$ & $6 / 45$ & $85 / 63$ \\
\hline & Workday off-peak time & $37 / 37$ & $3 / 70$ & $6 / 45$ & $54 / 35$ \\
\hline & Weekend & $40 / 52$ & $3 / 98$ & $6 / 45$ & $54 / 48$ \\
\hline
\end{tabular}

\section{Methods and Results}

\subsection{Exploratory Factor Analysis (EFA)}

Based on the second part of the survey data, EFA was conducted to identify the common variables that reflect respondents' attitudes towards car-sharing. A total of 345 samples were involved in the EFA test, and factor analysis function provided by software SPSS version 22.0 was employed to carry out the test. The results are reported in Table 5, and a three-factor structure has been obtained. Specifically, the Kaiser-MeyerOlkin value was 0.766 , greater than the recommended value of 0.7 [46]. Meanwhile, the sum of the variance explained by the extracted three factors accounted for $83.076 \%$ of the total, greater than the suggested value of $80 \%$ [47]. Therefore, the three-factor structure was demonstrated to be acceptable. According to the factor loads, Factor 1 mainly reflects respondents' subjective attitudes on whether car-sharing services were easy to use, safe and reliable. Factor 2 can be defined as the variable that measured the perceived usefulness of car-sharing, while Factor 3 can be used to assess respondents' willingness to use car-sharing services. The three latent variables are denoted as $\eta_{1}, \eta_{2}$, and $\eta_{3}$, respectively.

Table 5. Descriptive statistics and factor analysis results.

\begin{tabular}{|c|c|c|c|c|c|}
\hline Variable & Mean & Std. Dev & Factor $1\left(\eta_{1}\right)$ & Factor $2\left(\eta_{2}\right)$ & Factor $3\left(\eta_{3}\right)$ \\
\hline $\mathrm{Y}_{1}$ & 3.970 & 0.961 & & & 0.778 \\
\hline $\mathrm{Y}_{2}$ & 3.570 & 1.032 & & & 0.785 \\
\hline $\mathrm{Y}_{3}$ & 3.800 & 0.966 & & & 0.793 \\
\hline $\mathrm{Y}_{4}$ & 3.600 & 0.995 & 0.844 & & \\
\hline $\mathrm{Y}_{5}$ & 3.590 & 0.970 & 0.846 & & \\
\hline $\mathrm{Y}_{6}$ & 3.950 & 0.960 & & 0.720 & \\
\hline $\mathrm{Y}_{7}$ & 3.740 & 0.971 & & 0.858 & \\
\hline $\mathrm{Y}_{8}$ & 3.950 & 0.901 & & 0.813 & \\
\hline $\mathrm{Y}_{9}$ & 3.680 & 0.972 & 0.888 & & \\
\hline $\mathrm{Y}_{10}$ & 3.730 & 0.959 & 0.862 & & \\
\hline \multicolumn{3}{|c|}{ Kaiser-Meyer-Olkin } & \multicolumn{3}{|c|}{0.766 (significance level $p<0.001$ ) } \\
\hline \multicolumn{3}{|c|}{ Total explained variance } & \multicolumn{3}{|c|}{$83.076 \%$} \\
\hline
\end{tabular}

Note: After varimax rotation, factor loads below 0.4 were omitted.

\subsection{Path Analysis}

Path analysis can be considered as a kind of multiple regression technology. In this study, path analysis was used to evaluate the effects of socio-demographic variables on respondents' attitudes towards car-sharing services (i.e., $\eta_{1}, \eta_{2}$ and $\eta_{3}$ ). The path diagram is constructed as shown in Figure 1, where $\eta_{n}$ denotes $\eta_{1}, \eta_{2}$ and $\eta_{3} ; Y_{n}$ represents the vector of observed variables employed to measure $\eta_{n}$ and $X_{n}$ denotes the vector of sociodemographic variables, including gender, grade, disposable income, etc. 


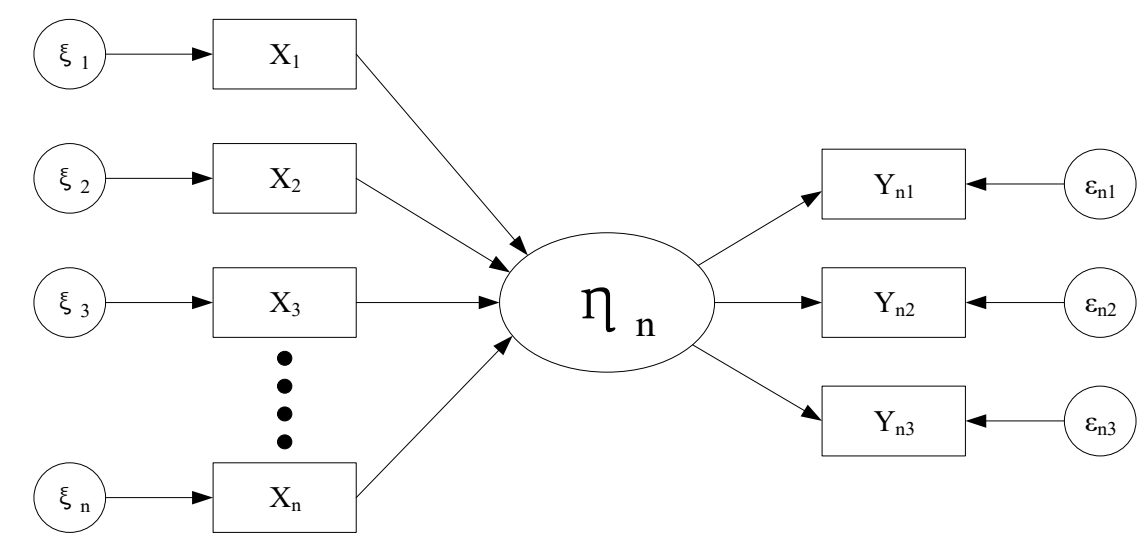

Figure 1. The path diagram for evaluating observed variables on latent attitudes.

Specifically, the path diagram (Figure 1) can be described using the following linear equations, Equations (1) and (2), where $\Lambda$ denotes the matrix of factor loads, and $\varepsilon_{n}$ denotes the error term corresponding to each measurement [8]. Moreover, $\Gamma$ denotes the regression coefficients to be estimated and $\xi_{n}$ denotes measurement error terms.

$$
\begin{aligned}
& Y_{n}=\Lambda \eta_{n}+\varepsilon_{n} \\
& \eta_{n}=\Gamma X_{n}+\xi_{n}
\end{aligned}
$$

The results of path analysis are shown in Table 6, where the effects of individual differences on respondents' attitudes towards car-sharing are illustrated. Specifically, at the significance level of $5 \%$, it was found that male students exhibited more positive attitudes than female students $(-0.148)$ on the perceived service guarantee $\left(\eta_{1}\right)$. This is potentially because females are more sensitive to personal safety and ease of use of car-sharing. In addition, it also indicated that college students with more driving experience $(0.100)$ or who had used car-sharing services before (0.364) were more likely to show optimistic attitudes on this aspect. The results were in line with previous studies, because rich experiences would improve users' sense of safety and reduce concerns about the uncertainties of such services. As for the perceived usefulness $\left(\eta_{2}\right)$, grade was found to exert a slightly negative influence $(-0.037)$, thereby indicating that higher grade students were more likely to disagree with the usefulness of car-sharing. Additionally, the respondents who had ever used car-sharing services (0.314) offered positive outlooks on the perceived usefulness. This is likely because previous experience may strengthen the users' attitudes on the usefulness of car-sharing services. With respect to the willingness to use car-sharing services $\left(\eta_{3}\right)$, female students showed a higher intention to use car-sharing services than male students (0.127). Separately, monthly disposable income was demonstrated to have negative effects on car-sharing use. Moreover, previous experiences with car-sharing $(0.380)$ was found to have positive effects on re-patronage. 
Table 6. Effects of socio-economic indicators on latent attitudes ( $t$-values).

\begin{tabular}{|c|c|c|c|}
\hline \multirow[b]{2}{*}{ Indicators } & \multicolumn{3}{|c|}{ Latent Variables of Attitudes } \\
\hline & $\begin{array}{c}\eta_{1} \\
\text { (Service Guarantee) }\end{array}$ & $\begin{array}{c}\eta_{2} \\
\text { (Perceived Usefulness) }\end{array}$ & $\begin{array}{c}\eta_{3} \\
\text { (Willingness-of-Use) }\end{array}$ \\
\hline \multicolumn{4}{|l|}{ Gender } \\
\hline Female & $-0.148(-4.215)$ & / & $0.127(3.401)$ \\
\hline Grade & - & $-0.037(-5.535)$ & - \\
\hline Disposable income & - & - & $-0.051(-4.632)$ \\
\hline \multicolumn{4}{|l|}{ Disciplines } \\
\hline Social science & $0.143(4.112)$ & $0.111(3.507)$ & $0.167(4.845)$ \\
\hline Art & $0.276(2.964)$ & - & - \\
\hline Driving experience & $0.100(4.769)$ & - & - \\
\hline Use experience of Car-sharing & $0.364(5.661)$ & $0.314(5.205)$ & $0.380(5.792)$ \\
\hline
\end{tabular}

Note: When DF is more than 1000, the cutoff value for the $t$-test is 1.962 (at $5 \%$ significance level).

In short, socio-demographic variables were commonly regarded as controlling variables that were involved in the causal model of transport mode choice [48]. However, the above results show that these controlling variables were likely to affect the transport mode choice by exerting an impact on individuals' latent attitudes towards the transport mode. Therefore, in this study, the latent variables that measured respondents' attitudes towards car-sharing services were incorporated into a causal model, resulting in a hybrid model with both observed and latent variables.

\subsection{Hybrid Choice Model}

A hybrid binary logit model was used to examine the key factors that affected respondents' adoption of car-sharing. The dependent variable of the model was binary, denoted as whether the respondent was willing to use car-sharing services or not with regards to each travel scenario. Therefore, the model can be described as follows:

$$
\begin{gathered}
P_{n}=\frac{\exp \left(V_{n}\right)}{1+\exp \left(V_{n}\right)} \\
V_{n}=\beta_{x} Z_{n}+\beta_{\eta} \eta_{n}+C
\end{gathered}
$$

where $P_{n}$ denotes the likelihood of the respondent $n$ to use car-sharing services and $V_{n}$ represents the utility car-sharing perceived by the respondent $n$. In addition, in the utility function of $V_{n}, Z_{n}$ denotes the vector of independent observed variables, and $\eta_{n}$ represents the vector of independent latent variables. In this respect, the independent observed variables include the trip attributes involved in each scenario (trip distance, time to depart, the number of travel fellows, travel cost), while the independent latent variables are denoted as respondents' attitudes towards car-sharing services $\left(\eta_{1}, \eta_{2}, \eta_{3}\right)$. Moreover, $\beta_{x}$ and $\beta_{\eta}$ denote the parameters of independent variables to be estimated, and $C$ denotes the constant.

In this study, each respondent was asked to state their willingness to use car-sharing services with regard to each hypothetical scenario. Thus, a total of 3105 samples were generated from 345 respondents (each respondent was given nine travel scenarios). Then, the hybrid choice model was estimated using R language. The Hosmer-Lemeshow test was employed to assess the overall goodness-of-fit of the model. Results were concluded as shown in Table 7, where insignificant independent variables were omitted. The results indicate that the model was well fitted, since the $p$-value (0.177) exceeded the recommended value at the $5 \%$ significance level. 
Table 7. Results of the hybrid choice model.

\begin{tabular}{|c|c|c|c|c|}
\hline Variables & Estimates $(\beta)$ & S.E. & $\operatorname{Exp}(\beta)$ & $p$ Value \\
\hline No. of Fellows & & & & $0.000^{* * *}$ \\
\hline $1-2$ persons vs. 0 person & 1.305 & 0.133 & 3.689 & $0.000^{* * *}$ \\
\hline$\geq 3$ persons vs. 0 person & 1.754 & 0.112 & 5.780 & $0.000^{* * *}$ \\
\hline Time to use & & & & $0.000^{* * *}$ \\
\hline Off-peak time vs. peak time & 0.740 & 0.107 & 2.097 & $0.000 * * *$ \\
\hline Weekend vs. peak time & 0.369 & 0.115 & 1.447 & $0.001^{* * *}$ \\
\hline The perceived usefulness of car-sharing & 0.282 & 0.045 & 1.325 & $0.000^{* * *}$ \\
\hline \multicolumn{5}{|l|}{ Car-sharing EXP } \\
\hline Ever used & 0.476 & 0.148 & 1.610 & $0.001 * * *$ \\
\hline Disciplines & & & & $0.000 * * *$ \\
\hline Social science vs. natural science & 0.340 & 0.085 & 1.405 & $0.000 * * *$ \\
\hline Art vs. natural science & 0.184 & 0.221 & 1.203 & 0.404 \\
\hline Money cost for car-sharing & -0.115 & 0.005 & 0.891 & $0.003^{* * *}$ \\
\hline Constant & -2.034 & 0.177 & 0.131 & $0.000^{* * *}$ \\
\hline Hosmer and Lemeshow Test & \multicolumn{4}{|c|}{$p=0.177>0.050$} \\
\hline
\end{tabular}

\section{Discussions}

According to the results of the model, we found that when the number of travel fellows increased, the odds of using car-sharing services became much greater. Specifically, considering solo travel as the base category, the odds of using car-sharing services increased by almost three times (3.689) when one to two persons joined the trip. Furthermore, the odds increased by almost five times (5.780) when three or more persons joined the trip. To the best of our knowledge, this finding was rarely mentioned in the previous studies. However, from another point of view, this result confirms the effect of the sharing economy on covering environmental issues by fostering shared mobility. In addition, the results indicate that college students in China are more likely to use car-sharing services during workday off-peak hours and weekends. The reasons were twofold. First, as we discussed, non-commuting trips dominated the travel demands of college students in China. Second, during the morning rush hour, the advantages of using public transport were more obvious, because of the implementation of bus-only lanes and the time reliability of the metro system. Moreover, it was not surprising to find a positive effect of previous experience with carsharing (0.476), thereby indicating that college students who had used car-sharing services before were more willing to continue doing so. However, it was unexpected to find time cost did not have significant effects on the choice of car-sharing, while money spent on carsharing services $(-0.115)$ exerted a negative impact on the willingness-of-use. The reason could be that college students in China are more sensitive to money costs, because they generally reported sufficient disposable time but limited disposable income. In addition to the investigation of independent observed variables, the effects of latent variables that represented respondents' attitudes on car-sharing were also examined. Nevertheless, only the perceived usefulness (0.282) was found to have significant impact on the willingness to use car-sharing services. This implies that promoting the positive attitudes of college students in China on the usefulness of car-sharing would result in their more patronage.

Other than theoretical implications provided by the model, this study also offers practical suggestions for car-sharing service providers in China. Based on the above results, three particular aspects are emphasized as follows. First, prior experience with car-sharing was found to exert a positive influence on respondents' attitudes on the usefulness of car-sharing, which was demonstrated to promote car-sharing willingness-of-use. Therefore, test-drive services could be provided at designated stations to allow college students to gain more car-sharing experience. Second, the results revealed that college students in China exhibited a higher possibility of using car-sharing services when travelling with multiple companions. Thus, in order to further encourage college students to travel 
together and share a car, high-occupancy vehicles (HOV) could be charged at a discount. Third, since college students were more sensitive to the money cost of car-sharing, student memberships should be added, and discounted charging standards should be established for this member group.

\section{Conclusions}

College students are regarded as a large promising customer group of car-sharing markets in China. However, the significant differences between college students in China and the counterparts in Western countries made part of the findings rendered by previous studies not generalizable. Therefore, this paper investigated the key factors that influence college students in China to adopt car-sharing. An empirical study at Dalian Maritime University was conducted, and conclusions were drawn as follows.

As for the theoretical implications, several findings in this study were in line with previous studies. For instance, money costs exerted a negative impact on college students' willingness to use car-sharing services, while previous experience with car-sharing exhibited positive effects on intention to reuse. The research on college students in China in the context of car-sharing also led to new findings. Specifically, we found that when the number of travel fellows or companions increases, the odds of choosing car-sharing become greater. Moreover, time cost was demonstrated to have no significant impact on willingness to use car-sharing services. Additionally, college students in China were more likely to use car-sharing services during workday off-peak hours and weekends. Other than theoretical implications, practical suggestions are also rendered for car-sharing service providers. Specifically, based on the empirical study on survey data, we determined targeted countermeasures, including providing test-drive services for college students, allowing differentiated charging standards for student memberships and offering a discount for high-occupancy vehicles (HOV).

With respect to the limitations of this study, other potentially relevant factors (e.g., social norms, status symbols, ownership of mobility tools, trip purposes, service level of public transport around the university, timetable of lessons) should be accounted for in further studies. In addition, the use of student samples collected from a single university could be another major limitation. Thus, horizontal experiments should be designed in the future by using data across several universities. On this basis, more reliable results could be obtained, and common factors influencing college students' patronage to car-sharing services in China would be uncovered.

Author Contributions: Conceptualization, S.S.; Data curation, Y.L. and Y.Y.; Writing—original draft, S.S.; Writing - review and editing, Z.D. and X.W. All authors have read and agreed to the published version of the manuscript.

Funding: This research was funded by the Ministry of Education of Humanities and Social Science, Project (20YJCZH139).

Data Availability Statement: The data presented in this study are available on request from the corresponding author. The data are not publicly available due to the protection of individual's privacy.

Conflicts of Interest: The authors declare no conflict of interest.

\section{References}

1. Mensah, I.K.; Zhao, T.Y.; Zeng, G.H.; Luo, C.Y. Determinants of the continued intention of college students in china to use didi mobile car-sharing services. SAGE Open 2019, 9, 16. [CrossRef]

2. Ma, F.; Guo, D.; Yuen, K.F.; Sun, Q.; Ren, F.; Xu, X.; Zhao, C. The influence of continuous improvement of public car-sharing platforms on passenger loyalty: A mediation and moderation analysis. Int. J. Environ. Res. Public Health 2020, 17, 2756. [CrossRef] [PubMed]

3. Ullah, I.; Liu, K.; Vanduy, T. Examining travelers' acceptance towards car sharing systems—Peshawar City, Pakistan. Sustainability 2019, 11, 808. [CrossRef]

4. Docherty, I.; Marsden, G.; Anable, J. The governance of smart mobility. Transp. Res. Part A Policy Pract. 2018, 115, 114-125. [CrossRef] 
5. Mattia, G.; Mugion, R.G.; Principato, L. Shared mobility as a driver for sustainable consumptions: The intention to re-use free-floating car sharing. J. Clean. Prod. 2019, 237, 117404. [CrossRef]

6. Hui, Y.; Wang, Y.; Sun, Q.; Tang, L. The impact of car-sharing on the willingness to postpone a car purchase: A case study in Hangzhou, China. J. Adv. Transp. 2019, 2019, 1-11. [CrossRef]

7. Ramos, M.S.E.; Bergstad, C.J.; Chicco, A.; Diana, M. Mobility styles and car sharing use in Europe: Attitudes, behaviours, motives and sustainability. Eur. Transp. Res. Rev. 2020, 12, 1-12. [CrossRef]

8. Jin, F.L.; Yao, E.J.; An, K. Understanding customers' battery electric vehicle sharing adoption based on hybrid choice model. J. Clean Prod. 2020, 258, 13. [CrossRef]

9. Bi, J.; Zhi, R.; Xie, D.-F.; Zhao, X.-M.; Zhang, J. Capturing the characteristics of car-sharing users: Data-driven analysis and prediction based on classification. J. Adv. Transp. 2020, 2020, 1-11. [CrossRef]

10. Wang, W.; Zhang, Q.; Peng, Z.; Shao, Z.; Li, X. An empirical evaluation of different usage pattern between car-sharing battery electric vehicles and private ones. Transp. Res. Part A Policy Pract. 2020, 135, 115-129. [CrossRef]

11. Prieto, M.; Stan, V.; Baltas, G.; Lawson, S. Shifting consumers into gear: Car sharing services in urban areas. Int. J. Retail. Distrib. Manag. 2019, 47, 552-570. [CrossRef]

12. Mounce, R.; Nelson, J. On the potential for one-way electric vehicle car-sharing in future mobility systems. Transp. Res. Part A Policy Pract. 2019, 120, 17-30. [CrossRef]

13. Prieto, M.; Baltas, G.; Stan, V. Car sharing adoption intention in urban areas: What are the key sociodemographic drivers? Transp. Res. Part A Policy Pract. 2017, 101, 218-227. [CrossRef]

14. de Luca, S.; Di Pace, R. Modelling users' behaviour in inter-urban carsharing program: A stated preference approach. Transp. Res. Part A Policy Pract. 2015, 71, 59-76. [CrossRef]

15. Sai, Q.; Bi, J.; Xie, D.; Guan, W. Identifying and predicting the expenditure level characteristics of car-sharing users based on the empirical data. Sustainability 2019, 11, 6689. [CrossRef]

16. Bojković, N.; Jeremic, V.; Petrovic, M.; Tica, S. Preferences for car sharing service attributes among university students: Evidence from an emerging market. J. East Eur. Manag. Stud. 2019, 24, 636-653. [CrossRef]

17. Rotaris, L.; Danielis, R.; Maltese, I. Carsharing use by college students: The case of Milan and Rome. Transp. Res. Part A Policy Pract. 2019, 120, 239-251. [CrossRef]

18. Martin, E.W.; Shaheen, S.A. Greenhouse gas emission impacts of carsharing in North America. IEEE Trans. Intell. Transp. Syst. 2011, 12, 1074-1086. [CrossRef]

19. Chen, Z.; Van Lierop, D.; Ettema, D. Dockless bike-sharing systems: What are the implications? Transp. Rev. 2020, 40, 333-353. [CrossRef]

20. Zheng, J.; Scott, M.; Rodriguez, M.; Sierzchula, W.; Platz, D.; Guo, J.Y.; Adams, T.M. Carsharing in a university community: Assessing potential demand and distinct market characteristics. Transp. Res. Rec. 2009, 2110, 18-26. [CrossRef]

21. Danielis, R.; Rotaris, L.; Rusich, A.; Valeri, E. The potential demand for carsharing by university students: An Italian case study. Sci. Reg. 2016, 15, 77-99. [CrossRef]

22. Danielis, R.; Rotaris, L.; Rusich, A.; Valeri, E. Understanding the demand for carsharing: Lessons from italian case studies. Int. J. Transp. Econ. 2014, 41, 327-359.

23. Zhou, J. Study of Employee Carsharing on the University Campus. J. Urban Plan. Dev. 2013, 139, 301-310. [CrossRef]

24. Efthymiou, D.; Antoniou, C.; Waddell, P. Factors affecting the adoption of vehicle sharing systems by young drivers. Transp. Policy 2013, 29, 64-73. [CrossRef]

25. Dias, F.F.; Lavieri, P.S.; Garikapati, V.M.; Astroza, S.; Pendyala, R.M.; Bhat, C.R. A behavioral choice model of the use of car-sharing and ride-sourcing services. Transportation 2017, 44, 1307-1323. [CrossRef]

26. Ko, J.; Ki, H.; Lee, S. Factors affecting carsharing program participants' car ownership changes. Transp. Lett. 2017, 11, 208-218. [CrossRef]

27. Yoon, T.; Cherry, C.R.; Jones, L.R. One-way and round-trip carsharing: A stated preference experiment in Beijing. Transp. Res. Part D Transp. Environ. 2017, 53, 102-114. [CrossRef]

28. Hjorteset, M.A.; Bcker, L. Car sharing in Norwegian urban areas. Transp. Res. d-Transp. 2020, 84, 102322. [CrossRef]

29. Paundra, J.; Rook, L.; Dalen, J.V.; Ketter, W. Preferences for car sharing services: Effects of instrumental attributes and psychological ownership. J. Environ. Psychol. 2017, 53, 121-130. [CrossRef]

30. Acheampong, R.A.; Siiba, A. Modelling the determinants of car-sharing adoption intentions among young adults: The role of attitude, perceived benefits, travel expectations and socio-demographic factors. Transportation 2020, 47, 2557-2580. [CrossRef]

31. Martínez, L.M.; Correia, G.H.D.A.; Moura, F.; Lopes, M.M. Insights into carsharing demand dynamics: Outputs of an agent-based model application to Lisbon, Portugal. Int. J. Sustain. Transp. 2016, 11, 148-159. [CrossRef]

32. Kim, D.; Ko, J.; Park, Y. Factors affecting electric vehicle sharing program participants' attitudes about car ownership and program participation. Transp. Res. Part D Transp. Environ. 2015, 36, 96-106. [CrossRef]

33. Becker, H.; Ciari, F.; Axhausen, K.W. Comparing car-sharing schemes in Switzerland: User groups and usage patterns. Transp. Res. Part A Policy Pract. 2017, 97, 17-29. [CrossRef]

34. Kim, J.; Rasouli, S.; Timmermans, H. Satisfaction and uncertainty in car-sharing decisions: An integration of hybrid choice and random regret-based models. Transp. Res. Part A Policy Pract. 2017, 95, 13-33. [CrossRef] 
35. Kopp, J.; Gerike, R.; Axhausen, K.W. Do sharing people behave differently? An empirical evaluation of the distinctive mobility patterns of free-floating car-sharing members. Transportation 2015, 42, 449-469. [CrossRef]

36. Firnkorn, J. Triangulation of two methods measuring the impacts of a free-floating carsharing system in Germany. Transp. Res. Part A Policy Pract. 2012, 46, 1654-1672. [CrossRef]

37. Sioui, L.; Morency, C.; Trépanier, M. How carsharing affects the travel behavior of households: A case study of Montréal, Canada. Int. J. Sustain. Transp. 2013, 7, 52-69. [CrossRef]

38. Efthymiou, D.; Antoniou, C. Modeling the propensity to join carsharing using hybrid choice models and mixed survey data. Transp. Policy 2016, 51, 143-149. [CrossRef]

39. Shaheen, S.A.; Martin, E. Demand for carsharing systems in Beijing, China: An exploratory study. Int. J. Sustain. Transp. 2010, 4, 41-55. [CrossRef]

40. Coll, M.-H.; Vandersmissen, M.-H.; Thériault, M. Modeling spatio-temporal diffusion of carsharing membership in Québec City. J. Transp. Geogr. 2014, 38, 22-37. [CrossRef]

41. De Lorimier, A.; El-Geneidy, A.M. Understanding the factors affecting vehicle usage and availability in carsharing networks: A case study of communauto carsharing system from Montréal, Canada. Int. J. Sustain. Transp. 2013, 7, 35-51. [CrossRef]

42. Kim, J.; Rasouli, S.; Timmermans, H.J.P. The effects of activity-travel context and individual attitudes on car-sharing deci-sions under travel time uncertainty: A hybrid choice modeling approach. Transp. Res. d-Transp. 2017, 56, 189-202. [CrossRef]

43. Li, W.; Kamargianni, M. Steering short-term demand for car-sharing: A mode choice and policy impact analysis by trip distance. Transportation 2020, 47, 2233-2265. [CrossRef]

44. Ju, P.; Zhou, J.; Xu, H.L.; Zhang, J.T. Travelers' choice behavior of car sharing based on hybrid choice model. J. Transport. Syst. Eng. Inf. Technol 2017, 17, 7-13.

45. Cheng, X.; Fu, S.; de Vreede, G.-J. A mixed method investigation of sharing economy driven car-hailing services: Online and offline perspectives. Int. J. Inf. Manag. 2018, 41, 57-64. [CrossRef]

46. Sun, S.; Duan, Z. Modeling passengers' loyalty to public transit in a two-dimensional framework: A case study in Xiamen, China. Transp. Res. Part A Policy Pract. 2019, 124, 295-309. [CrossRef]

47. Sun, S.-C. Public transit loyalty modeling considering the effect of passengers' emotional value: A case study in Xiamen, China. J. Adv. Transp. 2018, 2018, 1-12. [CrossRef] [PubMed]

48. Birgillito, G.; Rindone, C.; Vitetta, A. Passenger mobility in a discontinuous space: Modelling access/egress to maritime barrier in a case study. J. Adv. Transp. 2018, 2018, 1-13. [CrossRef] 